\title{
Bacterial community dynamics in long-term operation of a pilot plant using aerobic granular sludge to treat pig slurry
}

\author{
A. Fra-Vázquez ${ }^{a}$, N. Morales ${ }^{a}$, M. Figueroa ${ }^{a}$, A. Val del Río ${ }^{a}$, L. Regueiro ${ }^{a}$, J.L. Campos ${ }^{b}$ \\ and A. Mosquera-Corral ${ }^{a}$
}

a Group of Environmental Engineering and Bioprocesses, Department of Chemical Engineering, Institute of Technology, University of Santiago de Compostela, 15705 Santiago de Compostela, Spain

${ }^{\mathrm{b}}$ Faculty of Engineering and Science, Universidad Adolfo Ibáñez, Avda. Padre Hurtado 750, Viña del Mar, Chile

* Corresponding author. Tel.: +34 881816739. E-mail address: andrea.fra@usc.es

\begin{abstract}
Aerobic granular sludge represents an interesting approach for simultaneous organic matter and nitrogen removal in wastewater treatment plants. However, the information about microbial communities in aerobic granular systems dealing with industrial wastewater like pig slurry is limited. Herein, bacterial diversity and dynamics were assessed in a pilot scale plant using aerobic granular sludge for organic matter and nitrogen elimination from swine slurry during more than 300 days. Results indicated that bacterial composition evolved throughout the operational period from flocculent activated sludge, used as inoculum, to mature aerobic granules. Bacterial diversity increased at the beginning of the granulation process and then declined due to the application of transient organic matter and nitrogen loads. The operational conditions of the pilot plant and the degree of granulation determined the microbial community of the aerobic granules. Brachymonas, Zoogloea and Thanera were attributed with structural function as they are able to produce extracellular polymeric substances to maintain the granular structure. Nitrogen removal was justified by partial nitrification (Nitrosomonas) and denitrification (Thauera and Zoogloea), while Comamonas was identified as the main organic matter oxidizing bacteria. Overall, clear links between bacterial dynamics and composition with process performance were found and will help to predict their biological functions in wastewater ecosystems improving the future control of the process.
\end{abstract}


Keywords: Aerobic process; Granular sludge; Bacterial diversity; Applied microbiology; Wastewater treatment

\section{Introduction}

Traditionally, slurry generated in the livestock sector has been applied to the ground as fertilizer. However, the use of large amounts of this waste containing high ammonia concentrations is responsible for the appearance of eutrophication and toxicity events in aquatic ecosystems. To protect them, this type of waste has to be treated before discharge. For this purpose, wastewater treatments based on anaerobic digestion are the most used for organic matter removal. However, nitrogen remains in the produced effluent mainly in the form of ammonium. Technologies based on aerobic granular sludge are considered nowadays as an alternative for simultaneous organic matter and nutrient removal from industrial wastewater ${ }^{1}$. Some of them operate in aerobic conditions and remove COD (accumulated as polyhydroxyalkanoate-PHA) and nitrogen, whereas others operate in alternating anaerobic/aerobic conditions to remove COD, $\mathrm{N}$ and $\mathrm{P}$. In all cases, the formed granules are compact multicellular structures with good settling properties that can cope with the treatment of large organic loading rates ${ }^{2}$. In general, the granular biomass is produced in sequencing batch reactors (SBR) operated under fixed conditions which include the existence of a feast-famine regime, application of short settling time and the presence of hydrodynamic shear forces ${ }^{3-5}$. Under these operational conditions the microorganisms with the ability to grow in the form of granules are selected inside the reactor.

Even though biological systems are normally considered as "black boxes" regarding reactor performance, there are research works that demonstrate that macro-scale observations respond to microbial population dynamics ${ }^{6,7}$. The identification of the microorganisms 
present in the biomass and the analysis of their evolution throughout time are increasing in importance to enhance and optimize the treatment processes ${ }^{8}$. In the case of aerobic granules, which are biofilm systems, the biomass is able to perform nitrification, denitrification and organic matter oxidation simultaneously ${ }^{9}$. Bacterial populations coexist inside the granules distributed in different layers in depth depending on their oxygen and nutrient requirements ${ }^{10}$. Aerobic processes take place mainly in the surface layers: nitrification carried out by ammonia oxidizing bacteria (AOB) and nitrite oxidizing bacteria (NOB), together with organic matter oxidation by heterotrophic bacteria (HB). Meanwhile, in the inner part of the granules denitrifying bacteria complete the nitrogen removal process. Besides microorganisms in charge of nitrogen and organic matter removal, other bacterial populations play an important role in the maintenance of the granular structure by means of the production of extracellular polymeric substances (EPS) ${ }^{11}$.

Changes in the microbial community during granule formation have been previously studied in lab scale reactors ${ }^{12,13}$. A variable set of microorganisms were identified as main populations in these systems, depending greatly on the biological processes taking place. In granules obtained under alternate anaerobic/aerobic conditions with organic matter, $\mathrm{N}$ and P removal, Zhang et al. ${ }^{12}$ found Accumulibacter, Nitrosospira and Thauera as main responsible for nutrient removal, whereas Weissbrodt et al. ${ }^{13}$ observed that granulation mechanisms depended on predominant organisms involved. In aerobic reactors, with organic matter and nitrogen removal, Thauera and Zoogloea played an important role in the granulation process, both with glucose-based synthetic feeding ${ }^{14}$ and modified piggery wastewater ${ }^{15}$. Nowadays, information regarding bacterial populations in aerobic granular systems at pilot scale and fed exclusively with industrial wastewater is missing. Gaining knowledge about the evolution and bacterial diversity inside the granular biomass could provide useful information about the start-up and the response to transient conditions which can lead to instabilities. 
In this research study, the effects of the operational conditions on the bacterial community dynamics using aerobic granular biomass to treat pig slurry have been studied. Correlations between bacterial populations and reactor performance during start-up and long-term operation under stable and transient conditions were established.

\section{Material and methods}

\subsection{SBR pilot reactor operation}

A pilot scale SBR plant with a working volume of $100 \mathrm{~L}$ and fed with swine slurry was operated during 307 days. The inoculum of the SBR was activated sludge collected from a municipal wastewater treatment plant. The granulation strategy was based on the establishment of a feast-famine regime throughout the operational cycle. Morales et al. ${ }^{16}$ described the operation of this reactor, which was divided in two different stages. In Stage I (days 1-76) the organic and nitrogen loading rates (OLR and NLR) were maintained at values of $1.91 \pm 0.34 \mathrm{~kg} \mathrm{COD}_{\mathrm{s}} /\left(\mathrm{m}^{3} \cdot \mathrm{d}\right)$ and $0.31 \pm 0.06 \mathrm{~kg} \mathrm{~N} /\left(\mathrm{m}^{3} \cdot \mathrm{d}\right)$, respectively, to promote the granulation process. Then, in Stage II (days 77-307) both loading rates were increased and varied in order to test the stability of the formed mature granules to changes on the feeding composition. Values of the OLR ranged from 1.75 to $6.26 \mathrm{~kg} \mathrm{COD}_{\mathrm{s}} /\left(\mathrm{m}^{3} \cdot \mathrm{d}\right)$ while those of the NLR increased up to $\left.1.00 \pm 0.27 \mathrm{~kg} \mathrm{~N} /\left(\mathrm{m}^{3} \cdot \mathrm{d}\right)\right)$.

\subsection{DNA extraction}

Biomass samples were sonicated for 1 minute at $65 \%$ of amplitude using a probe sonicator (UP200s, Dr. Hielscher). Total genomic DNA was extracted according to the phenolchloroform protocol ${ }^{17}$. DNA was suspended in $50 \mu \mathrm{L}$ of milliQ water and measured with Nanodrop (Biometra). The extracted DNA was kept at $-20^{\circ} \mathrm{C}$. 


\subsection{Denaturing Gradient Gel Electrophoresis (DGGE)}

DNA was extracted from samples of biomass collected on operating days 1 (inoculum), 5, 7, 9, 13, 19, 26, 35, 41, 58 (Stage I) and 90, 118, 132, 181, 212, 271, 307 (Stage II). Then, the highly variable region of $16 \mathrm{~S}$ rRNA gene of domain Bacteria was amplified by means of the Polymerase Chain Reaction (PCR) technique using as primers 968F and 1401R with the sequences

5'-

\section{CGCCCGGGGCGCGCCCCGGGCGGGGCGGGGGCACGGGGGGAACGCGAAC}

CT'TAC -3' (GC clamp underlined) and 5'-CGGTGTGTACAAGACCC-3', respectively ${ }^{18}$. PCR amplification was performed in a Veriti $^{\circledR}$ Thermal Cycler from Applied Biosystems (California, USA) using a PCR mixture containing 1.25 U of polymerase (TaKaRa ExTaq ${ }^{\mathrm{TM}}$ Hot Start Version; TaKaRa Bio Inc., Japan), 1X ExTaq Buffer (2 mM of $\left.\mathrm{MgCl}_{2}\right), 200 \mu \mathrm{M}$ of desoxinucleotide triphosphate (dNTPs), $0.5 \mu \mathrm{M}$ of each primer, $100 \mathrm{ng}$ of DNA, and sterile milliQ water to a final volume of $50 \mu \mathrm{L}$. The PCR conditions were as follows: 9 min of activation of the polymerase at $95^{\circ} \mathrm{C} ; 35$ cycles consisting of 1 min of denaturing at 94 ${ }^{\circ} \mathrm{C}, 1 \mathrm{~min}$ of annealing at $55^{\circ} \mathrm{C}$ and $90 \mathrm{~s}$ of synthesis at $72{ }^{\circ} \mathrm{C}$; and finally, an extension step at $72{ }^{\circ} \mathrm{C}$ for $10 \mathrm{~min}$. The PCR products were analysed by $1 \%$ [wt/vol] agarose gel electrophoresis to verify their length and the specificity of the amplification.

PCR-amplified fragments were separated by DGGE analysis ${ }^{19}$, in a $6 \%$ [wt/vol] polyacrylamide gel with a formamide/urea denaturing gradient ranging from 30 to $70 \%$ using an INGENY phorU system (Ingeny, Goes, The Netherlands). The gel was run for 16 $\mathrm{h}$ at $100 \mathrm{~V}$ in $1 \mathrm{xTAE}$ buffer maintained at $60^{\circ} \mathrm{C}$. Then, it was stained with $1 \mathrm{xTAE}$ buffer containing SYBRGold (Molecular Probes, Inc. Eugene, OR, USA) and visualized under UV transilluminator.

DGGE profiles were analysed using BioNumerics software v.6.1 (Applied Maths, SintMartens-Latem, Belgium). Profile similarities were obtained by the determination of the Jaccard index that evaluated the similarity among DGGE lanes in a range from $0 \%$ (no 
common band) to $100 \%$ (identical band patterns). Then, the corresponding dendrogram was built considering the band intensity by the unweighted pair group method with arithmetic mean algorithms (UPGMA). The range-weighted richness index (Rr) was calculated as the total number of bands multiplied by the percentage of denaturing gradient needed to describe the total diversity of the sample analysed ${ }^{20}$.

Predominant bands were excised from the gel with a sterile razor blade, suspended in 50 $\mu \mathrm{L}$ of sterile milliQ water and stored overnight at $4{ }^{\circ} \mathrm{C}$. Bands were re-amplified by PCR as described above, with the exception of the GC clamp linked to the forward primer, and sent to sequencing analysis. Sequencing was accomplished by using the ABI PRISM Big Dye Terminator Cycle Sequencing Ready Reaction Kit (version 3.1) and ABI PRISM 3700 automated sequencer (PE Applied Biosystems, Foster City, CA, USA) following the manufacturer's instructions. Partial 16S rRNA gene sequences of nearly 200 nucleotides of length were obtained. They were contrasted with nucleotide sequences from GeneBank database to get the closest organisms by using the BLAST server of the National Center for Biotechnology Information (http://blast.ncbi.nlm.nih.gov/Blast.cgi).

\subsection{S rRNA gene-based amplicon analysis}

The same samples were analysed by DGGE and 16S rRNA gene-based amplicon analysis. The sequence of the V3-V4 region of the 16S rRNA gene was used as the taxonomic basis to initially identify the bacterial populations present in the samples, according to Caporaso et al. ${ }^{21}$. Samples underwent two consecutive rounds of PCR analysis. The first round of PCR amplified the targeted region, while the second round of PCR attached the sample barcode and sequencing adapters. Samples of extracted DNA were amplified using specific primers with the following sequences: 806R (5'TCGTCGGCAGCGTCAGATGtgtatAAGAGACAG-3’) and 515F (5'GTCTCGTGGGCTCGGAGATGtGTATAAGAGACAG-3’). Positive amplification was 
evaluated by gel electrophoresis of PCR products, which showed a marked and clean band of a size around $460 \mathrm{pb}$ in most of the samples. A second PCR of low number of cycles was applied to add the individual barcode to each sample, as well as to incorporate specific sequences in the amplicon libraries. The adapter primers included the specific sequences, the unique barcodes and also the universal fusion sequences CS1 (ACACTGACGACATGGTTCTACA) and CS2 (TACGGTAGCAGAGACTTGGTCT).

The Fluidigm CS fusion sequences were used to avoid the generation of dimer products in any of the screening reactions. The use of barcoding allowed simultaneously sequencing amplicons from many samples using relatively few barcoded adapter primers, and afterwards assigning each sequence to the sample they were obtained from. Individual libraries were analysed using a Bioanalyzer 2100 (Agilent) to estimate the concentration of the specific PCR products and samples were subsequently pooled at equimolar ratios. PCR copies were further cleaned, quantified and the concentration was measured by real time PCR, using specific primers (Kapa Biosystems). Finally, samples were denatured and prepared at $12 \mathrm{pM}$ to be seeded into a Miseq flowcell (Illumina) and ran under a 2x250 paired-end sequencing procedure (Parque Científico de Madrid, Spain). A total amount of $>100,000$ reads were obtained for each of the analysed samples. After quality filtering and demultiplexing, data were analysed using the $16 \mathrm{~S}$ rRNA gene-based amplicon sequencing (Base Space, Illumina). Specifically, for the 13 samples extracted, 2,193,455 sequences were obtained after quality filtering with approximately an $8.4 \%$ of low quality sequences. The number of assigned reads per sample ranged between 145,883 and 196,232 with an average value of 168,727 reads per sample. MSR software was used for the analysis.

Bioinformatic assays were performed with predominant operational taxonomic units (OTUs), i.e. with abundance above $0.5 \%$ of the total observed OTUs. Samples from days 5, 7 and 9 were excluded due to the insufficient measurements during first operational days. Principal coordinate analysis (PCoA) was performed to visualize the divergence among 
samples during the whole experiment. Distance-based constrained redundancy analysis (dbRDA) was accomplished using the software $\mathrm{R}$ (2.13.1), via the capscale function in vegan package $^{22}$, in order to find the operational parameters that best explained the diversity observed in the unconstrained PCoA. Soluble COD, ammonium and volatile suspended solids (VSS) concentrations, as well as OLR and NLR were the included parameters in this analysis. Analysis of Variance (ANOVA) was used to determine if each constraining parameter added a significant amount of information to the constrained model $(p<0.05)^{23}$. The Variance Inflation Factors (VIF) were studied to evaluate if the constraints were redundant ${ }^{21}$. Non-significant or redundant parameters were discarded until all the constraining variables in the db-RDA were significant $(\mathrm{p}>0.05)$ and non-redundant (VIF score $<10)^{23,24}$. In addition, to analyse the alpha diversity, the sample libraries were rarefied using the vegan package in $\mathrm{R}$, via rarefaction function and calculation of Shannon-Weaver index.

\subsection{Fluorescent in situ hybridization (FISH)}

The identification of active bacterial populations was carried out by the Fluorescence in situ hybridization (FISH) technique. Inoculum was analysed, together with fresh biomass samples collected from the reactor on days 13, 35 and 56 (Stage I), and 118, 181 and 307 (Stage II). Then, biomass samples were disrupted and fixed with $4 \%$ [wt/vol] paraformaldehyde solution according to the procedure described by Amann et al. ${ }^{2225}$. Hybridization was performed at $46^{\circ} \mathrm{C}$ for 90 min, adjusting the percentages of formamide to each probe. Bacterial cells hybridized with the list of FISH probes shown in supplementary data (Table S.1). Details on oligonucleotide probes are available at probeBase $^{26}$. All probes were 5' labelled by fluorochromes FITC (Fluorescein-5-isocyanate) or Cy3 (Carbocyanine 3). DAPI (4, 6-diamidino-2-phenylindole) was used as universal dye for the detection of all DNA in samples. Fluorescence signals were captured using an 
acquisition system (Coolsnap, Roper Scientific Photometrics) coupled to an epifluorescence microscope (Axioskop 2, Zeiss, Germany). The semi-quantitative counting of the bacterial populations, based on biovolume fraction, was performed with DAIME software $^{27}$.

\section{Results and discussion}

\subsection{Bacterial populations and granular structure}

\subsubsection{Bacterial community dynamics}

Bacterial populations forming part of the structure of aerobic granules were studied by means of the DGGE and 16S rRNA gene-based amplicon analysis. DGGE profiles for Bacteria domain indicated that the taxonomic groups present in the system changed depending on the operational conditions (Figure 1). Band pattern profiles corresponding to the inoculum and the first operational days (5, 7 and 9) were significantly different from those corresponding to samples from the rest of the reactor performance. Changes on DGGE band profiles indicated that the imposed conditions during Stage I promoted the evolution of flocculent activated sludge, used as inoculum, to form aerobic granules. Then, in Stage II the OLR was increased and varied in a wide range of values, which resulted in variations of the detected bacterial populations. During this stage the number of observed bands per sample decreased from 12 (day 90) to 8 (day 307).

These variations in the bacterial community were observed in the UPGMA dendrogram (Figure 2), which indicated the presence of three main bacterial clusters corresponding to the different imposed operational conditions ${ }^{16}$. Samples collected in Stage I were placed in two clusters, one corresponding to first operational days and the other associated to the granulation process. These differences might be attributed to the progressive shortening of the settling time of the cycle, from 10 to 5 min, performed during the first 15 days of the operation to eliminate the flocculent biomass with bad settling properties (Cluster 1). 
During Stage I the OLR was maintained almost unchanged around $2 \mathrm{~kg}$ CODs $/\left(\mathrm{m}^{3} \cdot \mathrm{d}\right)$ to promote the formation of aerobic granules, which constituted cluster 2. The third cluster grouped samples from Stage II, when the stability of the mature granules was tested by increasing the OLR from 1 to $6 \mathrm{~kg}$ CODs $/\left(\mathrm{m}^{3} \cdot \mathrm{d}\right)$. Sample from day 90 was included in cluster 2 from Stage I probably due to the gradual adaptation of bacteria to new imposed operational conditions. Bacterial communities of clusters 2 and 3, with a similarity around $40 \%$, were phylogenetically closer than those from cluster 1 . These results indicated that granular biomass significantly differed from flocculent sludge, as expected according to the study by Winkler et al. ${ }^{28}$. By comparing flocculent and granular sludge, they concluded that the bacterial community in aerobic granular sludge moved away from its initial populations. Zhang et al. ${ }^{29}$ found the same clustering pattern by applying UPGMA but only investigating the population dynamics of AOB community. Similar results were obtained by Zhao et al. ${ }^{15}$, with modified piggery slurry and high OLR. However, they did not operate the system in such variable conditions to obtain the cluster 3 corresponding to Stage II as in the present study.

Bacterial diversity was evaluated by calculating the range-weight richness $(\mathrm{Rr})$ and the Shannon-Weaver index with DGGE and 16S rRNA gene-based amplicon analysis results, respectively (Figure S.1). The Rr index takes into account the number of bands per lane and their position in the DGGE. The higher this index is, the more habitable a certain environment is ${ }^{20}$. During the first operational days the Rr value was around 6 and then, once the granules started forming from day 9 on, it increased and varied from 30 to almost 60 during Stage I. Similar evolution was observed by Zhang et al. ${ }^{12}$ with samples of aerobic granular biomass performing COD, $\mathrm{N}$ and $\mathrm{P}$ removal. Afterwards, in Stage II, $\mathrm{Rr}$ progressively decreased and finally reached a value around 20 at the end of the experiment. This variation was likely due to the imposed variations in OLR and NLR, which promoted the development of certain bacterial groups with the consequent descent of the diversity of 
the bacterial community able to withstand these transient situations. Despite changes in the bacterial community during granulation process (Stage I) or variations in the loading rates (Stage II), the physical stability of the granules remained stable. The Shannon-Weaver index calculated with the OTUs obtained by $16 \mathrm{~S}$ rRNA gene-based amplicon analysis showed similar diversity values within samples (i.e. alpha-diversity). Differences in diversity index calculated with both techniques may be because DGGE only considers the most abundant populations (with an abundance higher than 2.3\%) and 16S rRNA gene-based amplicon analysis includes all the rare OTUs (abundance lower than $0.1 \%)^{30}$. According to these results, the dominant species detected by DGGE analysis experienced more changes throughout the operational periods and provoked larger variations in the richness than the low-abundant species. Bacterial community responded to changes by adapting to operational conditions to maintain the stability and the removal efficiency.

Macroscopic results showed that aerobic granules were formed after 9 days of operation ${ }^{16}$. Positive results for FISH probes identifying members of phylum Chloroflexi and Sphaerotilus natants were observed in samples corresponding to the inoculum, as both are very common heterotrophic bacteria in activated sludge ${ }^{31,32}$. A fast decrease of the abundance of filamentous-shape organisms occurred when the settling time of the SBR operational cycle was shortened and they were washed-out. Even though in previous studies filamentous bacteria showed a structural function in the stability of aerobic granules ${ }^{33}$, microbial results of the present study suggested that heterotrophic bacteria acquired the role of binding material, as it will be discussed in the following section.

According to DGGE results, bacterial community was composed by microorganisms belonging to phylum Verrucomicrobia and phylum Proteobacteria (Table 1). Members of class Deltaproteobacteria (Band 1) slightly appeared during first operational days and their presence became quite stable in Stage II. The function this group exerts in the formation of the mature granules was unknown. The Band 2, corresponding to class Gammaproteobacteria, 
appeared during the start-up of the granulation process and disappeared until the end of Stage II when it reappeared as a weak band in samples from days 271 and 307. According to the DGGE profile, genus Thauera (Band 3) disappeared from the system during first operational days but in Stage II (from day 90 on) it appeared as a stable band with weak intensity. Genus Brachymonas (Band 4), appeared only during Stage I. Members of families Verrucomicrobiaceae, Xanthomonadaceae and Comamonadaceae (Bands 5, 6, 7 and 8, respectively) progressively appeared during the Stage I as bands with a weak intensity. All of them became into the most intense bands from day 90 on and throughout Stage II but the intensity of those bands almost disappeared in the last two samples (days 271 and 307). The potential contribution of genus Thauera and genus Brachymonas to the structure of the granular matrix has been attributed to their ability to produce extracellular polymeric substances (EPS) ${ }^{11,34}$, helping cells to stay together. Genus Brachymonas played an essential role during the granulation start-up in Stage I whereas genus Thanera could take on that function once the mature granules were formed and the applied loading rates were increased. Therefore, these results suggested that different bacterial populations may be responsible for the granular structure maintenance and depending on the operational conditions the dominant bacterial group will change.

\subsubsection{Impact of operational parameters on the bacterial community}

Divergences among samples during the whole operation were analysed based on phylogenetic variations using principal component analysis (PCoA). Differences between Stages I and II were visualized (Figure 3A) as they were clearly separated into two groups. This observation fits with the results obtained by DGGE analysis, which showed different band profiles for samples corresponding to the granulation period and those from the stability tests period. Winkley et al. $^{28}$ observed the similar results with aerobic granular sludge from a pilot plant treating municipal wastewater. The bacterial populations in the 
aerobic granular sludge moved away from its initial population, representing a permanent change. The first two axes of the constrained redundancy analysis (db-RDA), i.e. RDA1 (34\%) and RDA2 (7\%)), explained approximately $40 \%$ of the phylogenetic variations shown by the first two axes of the unconstrained PCoA plot (i.e., PCoA1 (23\%) and PCoA2 (16\%)). Furthermore, db-RDA identified OLR and VSS concentration, among all the measured environmental parameters, as those that best explained the variation in bacterial community structure observed in PCoA (Figure 3B). In order to correlate these findings with the macroscopic results from the pilot reactor ${ }^{16}$, the evolution of both parameters is explained below.

Both parameters, identified by constrained redundancy analysis as those producing the most important effects on the evolution of bacterial populations, respond to the two most important changes in the reactor operation: the granular biomass formation and OLR transient conditions. The VSS concentration inside the reactor significantly increased at the beginning of Stage II, coinciding with the granular biomass formation, which seems to justify the observed changes in the bacterial community structure. This increment of VSS may be associated then to the development of bacteria with structural function. Genus Thanera was identified as the main population playing this role into the granules during this stage. Variations in the applied OLR were performed during Stage II to test the stability of the granules once they were formed in Stage I. The db-RDA plot showed changes in bacterial community during the last 100 days of operation that might be driven by this parameter (Figure 3B). According to Li et al. ${ }^{14}$, high organic loading rates promoted faster formation of larger granules, which may explain that in this research work the stability of the granules kept stable regardless of variations in the composition of the bacterial community.

\subsection{Bacterial populations and removal activities}




\subsubsection{Nitrifying Bacteria}

Ammonia Oxidizing Bacteria (AOB)

During the first operational days, no positive results for AOB were found coinciding with no ammonium oxidizing activity in the reactor. Around day 15 of operation, positive results for AOB belonging to class Betaproteobacteria (Nitrosomonas) were observed (Figure 4A). They were visualized as single cells randomly distributed, corresponding to an abundance of less than $5 \%$ which correlated with the low ammonium oxidizing activity of around $0.05 \mathrm{~g} \mathrm{NH}_{4}^{+}-\mathrm{N} /(\mathrm{g} \mathrm{VSS} \cdot \mathrm{d})$ measured in the reactor during this period. With the progressive increase of the average diameter of the granules, the spatial distribution of this group of microorganisms changed from individual cells to dense microcolonies (Figure 4B). It is known that $\mathrm{AOB}$ related to Nitrosomonas spp. usually form spherical, compact aggregates of $10-50 \mu \mathrm{m}$ due to a strong adhesion among cells ${ }^{32}$. On day 35 , the ammonia oxidizing microorganisms clusters corresponding to class Betaproteobacteria represented $10 \%$ of the whole bacterial populations when the ammonium oxidizing activity was around 0.12 $\mathrm{g} \mathrm{NH}_{4}{ }^{+}-\mathrm{N} /(\mathrm{g}$ VSS$\cdot \mathrm{d})$. The gradual increase of AOB abundance was related to the gradual increase of nitrite concentrations in the effluent due to the corresponding increase of ammonium oxidation activity during Stage I. This bacterial group kept on an abundance of $15 \%$ on day 56 when the activity value of $0.19 \mathrm{~g} \mathrm{NH}_{4}{ }^{+}-\mathrm{N} /(\mathrm{g}$ VSS $\cdot \mathrm{d})$ was reached. Then, these values decreased and ranged between 0.05 and $0.17 \mathrm{~g} \mathrm{NH}_{4}{ }^{+} \mathrm{N} /(\mathrm{g} \mathrm{VSS} \cdot \mathrm{d})$ throughout Stage II with a constant AOB abundance around 10\%. These positive results corresponded to Nitrosomonas spp. and Nitrosococcus mobilis (Figure 4C).

Despite FISH analysis showed the presence of AOB, this result was not confirmed by DGGE or 16S rRNA gene-based amplicon analysis. This was also observed by Zhao et al. ${ }^{15}$ with biomass samples from aerobic granular sludge treating piggery wastewater (Table 2) in short term experiments. They considered heterotrophic nitrification as the main process contributing to nitrogen removal in an aerobic granular sludge system at high COD 
and $\mathrm{N}$ loading rates. However, experimental results from this study revealed the occurrence of ammonium oxidizing activity due to the presence of nitrite in the effluent ${ }^{16}$. Wan et al. ${ }^{35}$ also obtained partial nitrification using aerobic granules firstly cultivated in a SBR at high COD concentration.

Nitrite Oxidizing Bacteria (NOB)

Specific FISH probes for NOB populations were applied and no positive signals were detected during almost the whole experiment. These results correlated with the low activity value (around $0.01 \mathrm{~g} \mathrm{NO}_{2}^{-}-\mathrm{N} /(\mathrm{g} \mathrm{VSS} \cdot \mathrm{d})$ ), which was considered insignificant. Only around day 60 larger amount of nitrate was measured in the effluent (50 $\left.\mathrm{mg} \mathrm{NO}_{3}{ }^{-} \mathrm{N} / \mathrm{L}\right)$, indicating the presence of $\mathrm{NOB}$ with an activity of $0.10 \mathrm{NO}_{2}^{-}-\mathrm{N} /(\mathrm{g} \mathrm{VSS} \cdot \mathrm{d})$. Positive results for phylum Nitrospirae were punctually found on day 56 corresponding to less than $8 \%$ of the total biomass (Figure 4D). This group of NOB is known as being adapted to low nitrite concentration $^{36}$. No positive results were observed for Nitrobacter spp.

Similar results were obtained by Lemaire et al. ${ }^{10}$ operating an aerobic granular SBR for COD, $\mathrm{N}$ and $\mathrm{P}$ removal (Table 2) and they attributed this absence to the presence of genus Accumulibacter, which outcompeted NOB for the oxygen. Also Vázquez-Padín et al. ${ }^{37}$ found this behaviour in a nitrifying granular system treating nitrogen loads up to $0.8 \mathrm{~g} \mathrm{NH}_{4}^{+}$$\mathrm{N} /(\mathrm{L} \cdot \mathrm{d})$, caused by dissolved oxygen limitations. However, Zhang et al. ${ }^{29}$ attributed the no presence of NOB to the granules size, being absent in granules larger than $0.9 \mathrm{~mm}$ (Table 2). However another explanation in this study could be attributed to the presence of free ammonia concentrations inhibitory for NOB. Anthonisen et al..$^{38}$ observed the inhibition of Nitrobacter growth by free ammonia at values of $0.1-1.0 \mathrm{mg} / \mathrm{L}$. In the present study, the $\mathrm{pH}$ in the reactor was $7.3 \pm 0.5$ and the free ammonia average values were $0.7 \mathrm{mg} / \mathrm{L}$ in Stage I and $0.3 \mathrm{mg} / \mathrm{L}$ in Stage II. Therefore, the absence of NOB can be attributed to the inhibition due to the presence of free ammonia. 


\subsubsection{Heterotrophic Bacteria}

Heterotrophic bacteria carrying out the organic matter oxidation, accumulating PHA, denitrifying and/or maintaining the granular structure were expected to be part of the aerobic granules ${ }^{39}$. Positive hybridizations were mostly found corresponding to class Betaproteobacteria (genera Comamonas, Thauera and Zoogloea). Members of genus Comamonas were identified and maintained an abundance of around 20\% (Figure 5A). However, during the last operational days their presence decreased to less than $5 \%$. During this period an increase of the non-biodegradable fraction of the total organic matter present in the feeding was observed, which led to a decrease of the organic matter removal percentage. This change in the available readily biodegradable fraction of the organic carbon could explain that the abundance of this heterotrophic bacteria group dropped off.

Members of genera Zoogloea and Thanera were two of the bacterial populations identified by DGGE and 16S rRNA gene-based amplicon analysis. Their presence was confirmed by applying specific FISH probes (Table S.1). Apart from organic matter oxidizing bacteria, both can be found in WWTPs as responsible for the denitrification process ${ }^{40}$. Members from genus Zoogloea were barely present in the inoculum and their abundance gradually increased to values in a range that varied from 20 to $30 \%$ in Stage I (Figure 5B). Then, during the second stage this value dropped to $15 \%$ till the end of the experiment. Zoogloea can also have a structural function as it excretes components which facilitate the adhesion among cells. FISH results suggested that genus Zoogloea could play that role during granulation stage together with Brachymonas, which has been previously identified. Weissbrodt et al. ${ }^{12}$ also found Zoogloea, along with Accumulibacter and Competibacter, as main populations involved in granulation process (Table 2). Positive results for genus Thanera were found in an abundance of less than $5 \%$ in the inoculum. Their abundance in the system increased until reaching, around day 56, a value of $15 \%$ of total biomass. During Stage II it continued increasing from $30 \%$ on day 118 to $60 \%$ at the end of the 
experimental period (Figure 5C). The great abundance of this group during second stage correlated with the results obtained by DGGE, where bands corresponding to genus Thauera remained stable all along the Stage II. Similar results were obtained by Weissbrodt et al. ${ }^{41}$, who identified Zoogloea-like microorganisms as relevant for the cohesion of granular biomass but not essential during the granule formation.

During the first operational days, the percentage of identified microorganisms corresponded to a low fraction of the total biomass present in the system (Figure 6). Then, with the formation of aerobic granular biomass, this value increased and during Stage II the fraction of biomass that remained unidentified was on average 15\%. As FISH results showed, changes in abundances for each bacterial group were observed all throughout the experiment. In this way, whereas genera Zoogloea and Comamonas decreased their abundance from day 56 to the end of the operation, member of genus Thauera gradually increased their presence in the system until becoming the most abundant group on day 307. These results suggested that genus Thauera adapted to an increase of OLR during Stage II. The other two genera could be progressively inactivated under those conditions. This trend was also confirmed with the results obtained by $16 \mathrm{~S}$ rRNA gene-based amplicon analysis. However, the values of the abundances for Thauera, Zoogloea and Comamonas were lower in this case (Figure S.2). This behavior could be attributed to the fact that the FISH technique is a semiquantitative method in which the probes hybridize not only at specific species but also at higher taxonomic level. Furthermore, the feast-famine regime established in the SBR selected PHA-accumulating organisms, like those belonging to genus Thanera. In this way, this bacterial group might use PHA as carbon source in order to carry out the observed denitrifying activity in the reactor. Previous studies reported genera from family Comamonadaceae (genus Acidovorax and Thanera) as bacteria performing the denitrification $\operatorname{process}^{40,42}$. 


\section{CONCLUSIONS}

The aerobic granule formation in a pilot scale reactor treating pig slurry was linked to the composition of the bacterial community. Structural function in granules was carried out by heterotrophic bacteria able to produce exopolymer substances. Genus Brachymonas played an essential role during the start-up of the granulation process while genus Thanera took on that function once the mature granules were formed. Variations in the operational conditions of the pilot plant determined the dynamics and diversity of the microorganisms. Aerobic granules kept stable regarding structure but bacterial populations changed to adapt to transient operational conditions, which allowed the maintenance of macroscopic removal activities. Bacterial diversity decreased due to OLR and NLR shifts, highlighting Thanera as the main population able to withstand those change. The presence of this genus also correlated with the increase in denitrifying activity. Main bacterial populations involved in ammonia and organic matter removal from pig slurry were Nitrosomonas and Comamonas, respectively. The maturity degree of the aerobic granules and the operational conditions of the pilot plant clearly determined the bacterial composition of the biomass treating pig slurry.

\section{ACKNOWLEDGEMENTS}

This work has been financed by FISHPOL (CTQ2014-55021-R) and GRANDSEA (CTM2014-55397-JIN) projects from the Spanish Government and co-funded by FEDER. The authors belong to the Galician Competitive Research Group GRC 2013-032, programme co-funded by FEDER, and CRETUS (AGRU2015/02). 


\section{REFERENCES}

1. Arrojo B, Mosquera-Corral A, Garrido JM, Méndez R. Aerobic granulation with industrial wastewater in sequencing batch reactors. Water Res. 2004;38:3389-3399.

2. Figueroa M, Val del Río A, Campos JL, Mosquera-Corral A, Méndez R. Treatment of high loaded swine slurry in an aerobic granular reactor. Water Sci Technol. 2011;63:18081814.

3. Tay JH, Ivanov V, Pan S, Tay STL. Specific layers in aerobically grown microbial granules. Lett Appl Microbiol. 2002;34:254-257.

4. Adav SS, Lee DJ, Show KY, Tay JH. Aerobic granular sludge: Recent advances. Biotechnol Adv. 2008;26:411-423.

5. Campos JL, Figueroa M, Mosquera-Corral A, Méndez R. Aerobic sludge granulation: state-of-the-art. IJEE. 2009;1:136-151.

6. Wagner M, Loy A. Bacterial community composition and function in sewage treatment systems. Curr Opin Biotechnol 2002;13:218-227.

7. Gonzalez-Martinez A, Osorio F, Morillo JA, Rodriguez-Sanchez A, Goncalez-Lopez J, Abbas BA, van Loosdrecht MCM. Comparison of bacterial diversity in full scale anammox bioreactors operated under different conditions. Biotechnol Prog 2015;31:14641472.

8. Read S, Marzorati M, Guimaraes BCM, BoonN. Microbial resource management revisited: successful parameters and new concepts. Appl Microbiol Biotechnol. 2011;90:861871.

9. Mosquera-Corral A, Vázquez-Padín JR, Arrojo B, Campos JL, Méndez R. Nitrifying granular sludge in a sequencing batch reactor. In: Bathe S, de Kreuk MK, McSwain B, Schwarzenbeck N. Aerobic Granular Sludge. London: IWA Publishing, 2005:63-70.

10. Lemaire R, Webb RI, Yuanm Z. Micro-scale observations of the structure of aerobic microbial granules used for the treatment of nutrient-rich industrial wastewater. ISME Journal. 2008;2:528-541.

11. Seviour T, Yuan Z, van Loosdrecht MCM, Lin Y. Aerobic sludge granulation: a tale of two polysaccharides?. Water Res. 2012;46:4803-4813. 
12. Zhang B, Jin M, Qiu Z, Liu H, Wang J, Li J. Microbial population dynamics during sludge granulation in an anaerobic-aerobic biological phosphorous removal system. Bioresource Technol. 2011;102:2474-2480.

13. Weissbrodt DG, Neu TR, Kuhlicke U, Rappaz Y, Holliger C. Assessment of bacterial and structural dynamics in aerobic granular biofilms. Front Microbiol. 2013;4:175.

14. Li A, Yang S, Li X, Gu J. Microbial population dynamics during aerobic sludge granulation at different organic loading rates. Water Res. 2008;42:3552-3560.

15. Zhao Y, Huang J, Zhao H, Yang H. Microbial community and $\mathrm{N}$ removal of aerobic granular sludge at high COD and N loading rates. Bioresource Technol. 2013;143:439-446.

16. Morales N, Figueroa M, Fra-Vázquez A, Val del Río A, Campos JL, Mosquera-Corral A, Méndez R. Operation of an aerobic granular pilot scale SBR plant to treat swine slurry. Process Biochem. 2013;48:1216-1221.

17. Alonso-Gutierrez J, Lekunberri I, Teira E, Gasol JM, Figueras A, Novoa B. Bacterioplankton composition of the coastal upwelling system of 'Ria de Vigo', NW Spain. FEMS Microbiol Ecol. 2009;70:493-505.

18. Yu Z, Morrison M. Comparisons of different hypervariable regions of rrs genes for use in fingerprinting of microbial communities by PCR-Denaturing Gradient Gel Electrophoresis. Appl Environ Microb. 2004;70:4800-4806.

19. Muyzer G, de Waal EC, Uitterlinden AG. Profiling of complex microbial populations by denaturing gradient gel electrophoresis analysis of polymerase chain reactionamplified genes coding for 16S rRNA. Appl Environ Microb. 1993;59:695-700.

20. Marzorati M, Wittebolle L, Boon N, Daffonchio D, Verstraete W. How to get more out of molecular fingerprints: practical tools for microbial ecology. Environ Microbiol. 2008;10:1571-1581.

21. Caporaso JG, Lauber CL, Walters WA, Berg-Lyions D, Lozupone CA, Turnbaugh PJ, Fierer N, Knight R. Global patterns of $16 \mathrm{~S}$ rRNA diversity at a depth of millions of sequences per sample. P Nat Acad Sci USA. 2010;108:4516-4522.

22. Oksanen J, Kindt R, Legendre P, O’Hara B, Stevens MHH, Oksanen MJ, Suggests MASS. The vegan package. Community ecology package. 2007; 10. 
23. Agler MT, Werner JJ, Iten LB, Dekker A, Cotta MA, Dien BS, Angenent LT. Shaping reactor microbiomes to produce the fuel precursor n-butyrate from pretreated cellulosic hydrolysates. Environ Sci Technol. 2012;46:10229-10238.

24. Regueiro L, Spirito CM, Usack JG, Hospodsky D, Werner JJ, Angenent LT. Comparing the inhibitory thresholds of dairy manure co-digesters after prolonged acclimation periods: Part 2-correlations between microbiomes and environment. Water Res. 2015;87:458-466.

25. Amann RI, Krumholz L, Stahl DA. Fluorescent-oligonucleotide probing of whole cells for determinative, phylogenetic and environmental studies in microbiology. $J$ Bacteriol. 1990;172:762-770.

26. Loy A, Maixner F, Wagner M, Horn M. ProbeBase - an online resource for rRNAtargeted oligonucleotide probes: new features. Nucleic Acids Res. 2007;35(suppl_1): D800-D804.

27. Daims H, Lucker S, Wagner M. Daime, a novel image analysis program for microbial ecology and biofilm research. Environ Microbiol. 2006;8:200-213.

28. Winkler MK, Kleerebezem R, de Bruin LM, Verherijen PJ, Abbas B, Habermacher J, van Loosdrecht MCM. Microbial diversity differences within aerobic granular sludge and activated sludge flocs. Appl Microbiol Biotechnol. 2013;97:7447-7458.

29. Zhang B, Chen C, Qiu Z, Jin M, Chen Z, Chen Z, Li J, Wang X, Wang J. Dynamic and distribution of ammonia-oxidizing bacteria communities during sludge granulation in an anaerobic-aerobic sequencing batch reactor. Water Res. 2001;45:6207-6216.

30. Lynch MD, Neufeld JD. Ecology and exploration of the rare biosphere. Nat Rev Microbiol. 2015;13:217-229.

31. Bjornsson L, Hugenholtz P, Tyson GW, Blackall LL. Filamentous Chloroflexi (green non-sulfur bacteria) are abundant in wastewater treatment processes with biological nutrient removal. Microbiology. 2002;148:2309-2318.

32. Nielsen H, Daims H, Lemmer H. FISH handbook for biological wastewater treatment. London: IWA Publishing, 2009.

33. Figueroa M, Val del Río A, Campos JL, Méndez R, Mosquera-Corral A. Filamentous bacteria existence in aerobic granular reactors. Bioproc Biosyst Eng. 2015;38:841-851. 
34. Andersson S, Dalhammar G, Kuttuva-Rajarao G. Influence of microbial interactions and EPS/polysaccharide composition on nutrient removal activity in biofilms formed by strains found in wastewater treatment systems. Microbiol Res. 2011;166:449-457.

35. Wan C, Sun S, Lee D, Liu X, Wang L, Yang X, Pan X. Partial nitrification using aerobic granules in continuous-flow reactor: Rapid startup. Bioresour Technol. 2013;142:517-522.

36. Schramm A, de Beer D, van den Heuvel JC, Ottengraf S, Amann R. Microscale distribution of populations and activities of Nitrosospira and Nitrospira spp. along a macroscale gradient in a nitrifying bioreactor: Quantification by in situ hybridization and the use of microsensors. Appl Environ Microb. 1999;65:3690-3696.

37. Vázquez-Padín JR, Figueroa M, Campos JL, Mosquera-Corral A, Méndez R. Nitrifying granular systems: A suitable technology to obtain stable partial nitrification at room temperature. Sep Purif Technol. 2010;74:178-186.

38. Anthonisen AC, Loehr RC, Prakasam TBS, Srinath EG. Inhibition of nitrification by ammonia and bitrous acid. J Water Pollut Control Fed. 1976;48:835-852.

39. Tay JH, Liu QS, Liu Y. Microscopic observation of aerobic granulation in sequential aerobic sludge blanket reactor. J Appl Microbiol. 2001;91:168-175.

40. Thomsen TR, Kong Y, Nielsen PH. Ecophysiology of abundant denitrifying bacteria in activated sludge. FEMS Microbiol Ecol. 2007;60:370-382.

41. Weissbrodt DG, Lochmatter S, Ebrahimi S, Rossi P, Maillard J, Holliger C. Bacterial selection during the formation of early-stage aerobic granules in wastewater treatment systems operated under wash-out dynamics. Front Microbiol. 2012;3:332.

42. Ginige MP, Keller J, Blackall LL. Investigation of an acetate-fed denitrifying microbial community by stable isotope probing, full-cycle rRNA analysis and Fluorescent in situ Hybridization-Microautoradiography. Appl Environ Microb. 2005;71:8683-8691. 


\section{FIGURE CAPTIONS}

Figure 1. DGGE profiles corresponding to biomass samples collected from the reactor throughout the whole operational time: numbers on the top of each lane correspond to the operational day of the sample collection.

Figure 2. UPGMA dendrogram based on the Jaccard Index and images of the granular biomass from samples collected during granulation (S. I) and stability test (S. II) periods.

Figure 3. A) PCoA of the major principal coordinates based on the pairwise weighted UniFrac distances matrix. B) Distance-Based Redundancy Analysis (db-RDA) showing the parameters that best explain the variation in microbial community based on the pairwise weighted UniFrac distances matrix. Black dots represent samples from Stage I and white dots represent samples from Stage II.

Figure 4. FISH images. (A) AOB (NEU653; Cy3, red) and all bacteria (EUB338 ${ }_{\text {mix }}$; FITC, green) [day 16]. (B) AOB (NEU653; Cy3, red) and all bacteria (EUB338 mix ; FITC, green) [day 35]. (C) Nitrosomonas (Nsm156; Cy3, red) and all bacteria (EUB338 $8_{\text {mix }}$; FITC, green) [day 135]. (D) Phylum Nitrospirae (Ntspa712; FITC, green) and all DNA (DAPI, blue) [day 56]. The bar represents $10 \mu \mathrm{m}$.

Figure 5. FISH images. (A) Comamonas (Cte; Cy3, red) and all bacteria (EUB338 ${ }_{\text {mix }}$; FITC, green) [day 35]. (B) Zoogloea lineage (Zra23a; Cy3, red) and all bacteria (EUB338 ${ }_{\text {mix }}$; FITC, green) [day 181]. (C) Thauera (MZ1; Cy3, red) and all DNA (DAPI, blue) [day 307]. The bar represents $10 \mu \mathrm{m}$.

Figure 6. Estimated abundances of active bacterial populations identified in the reactor by FISH technique. 


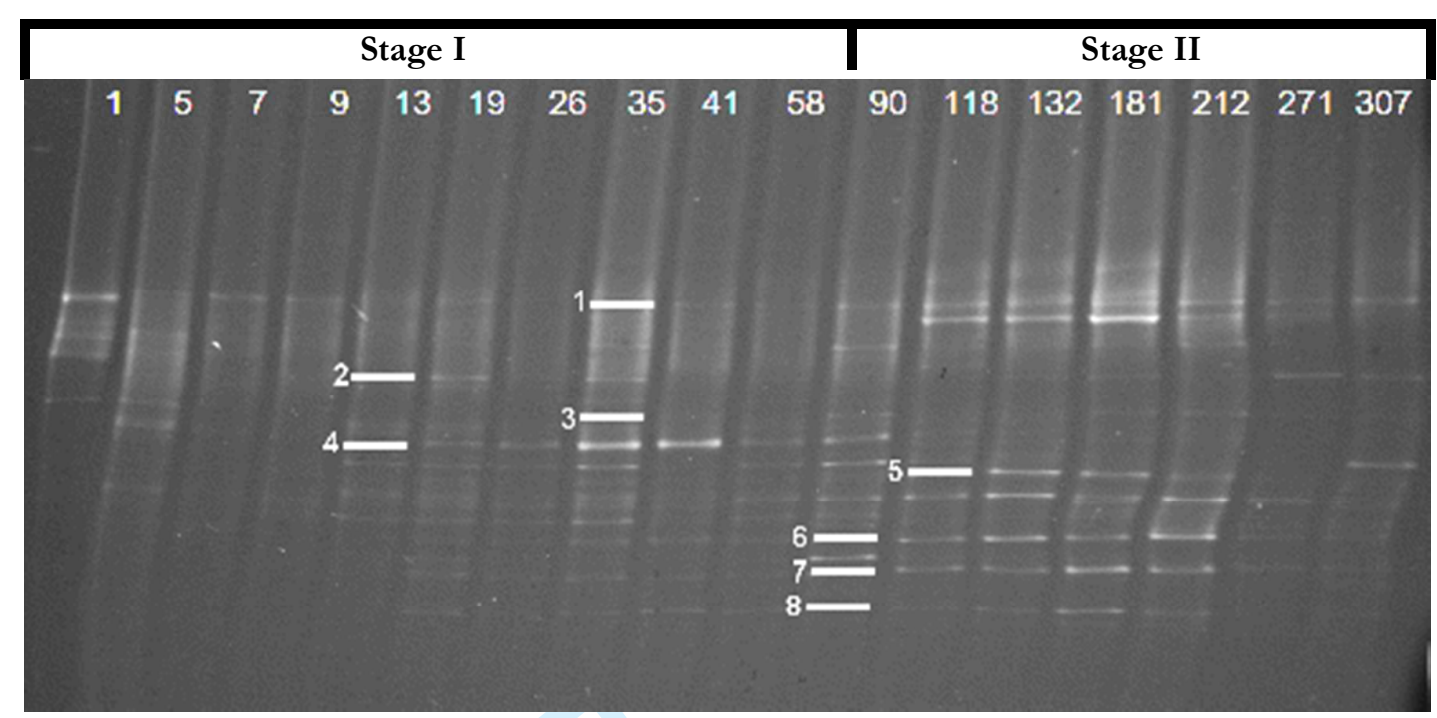

Figure 1 

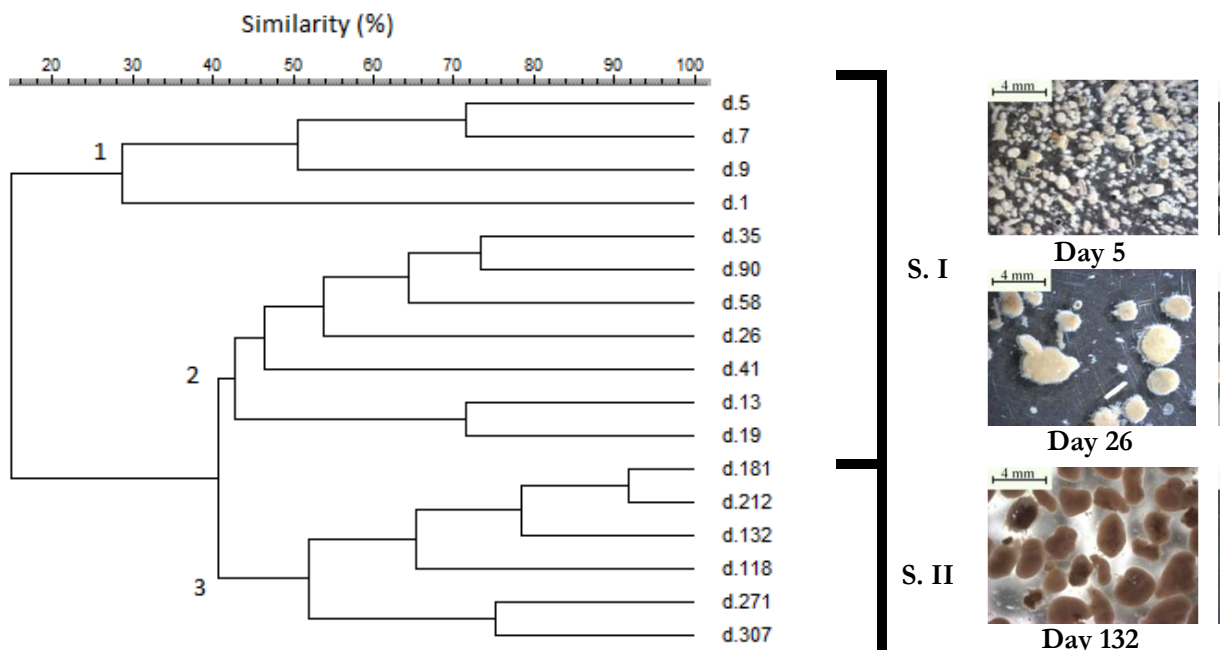

S. I

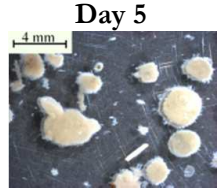

Day 26
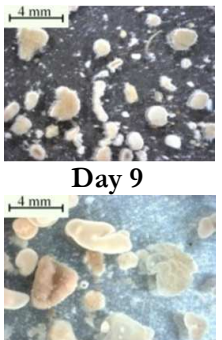

Day 90
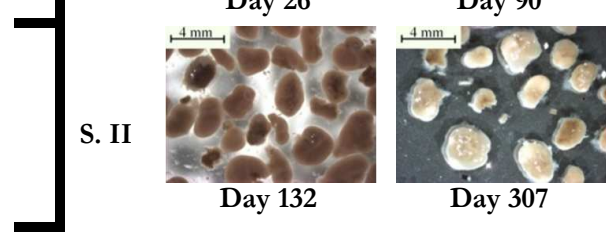

Figure 2 
A

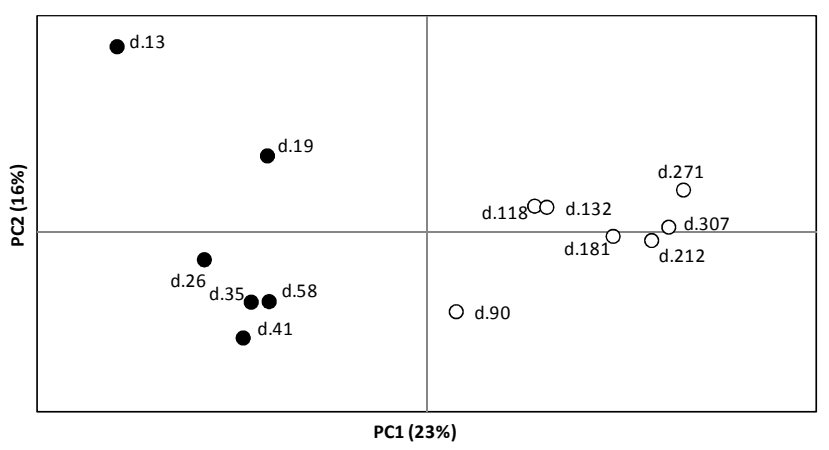

B

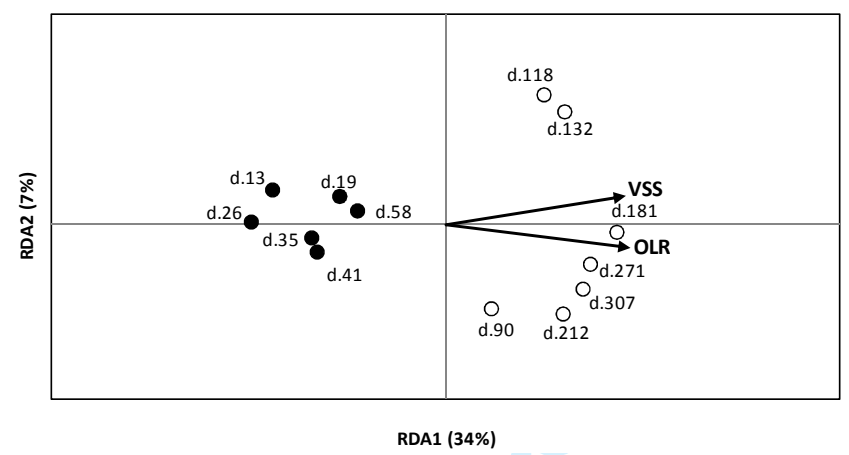

Figure 3 

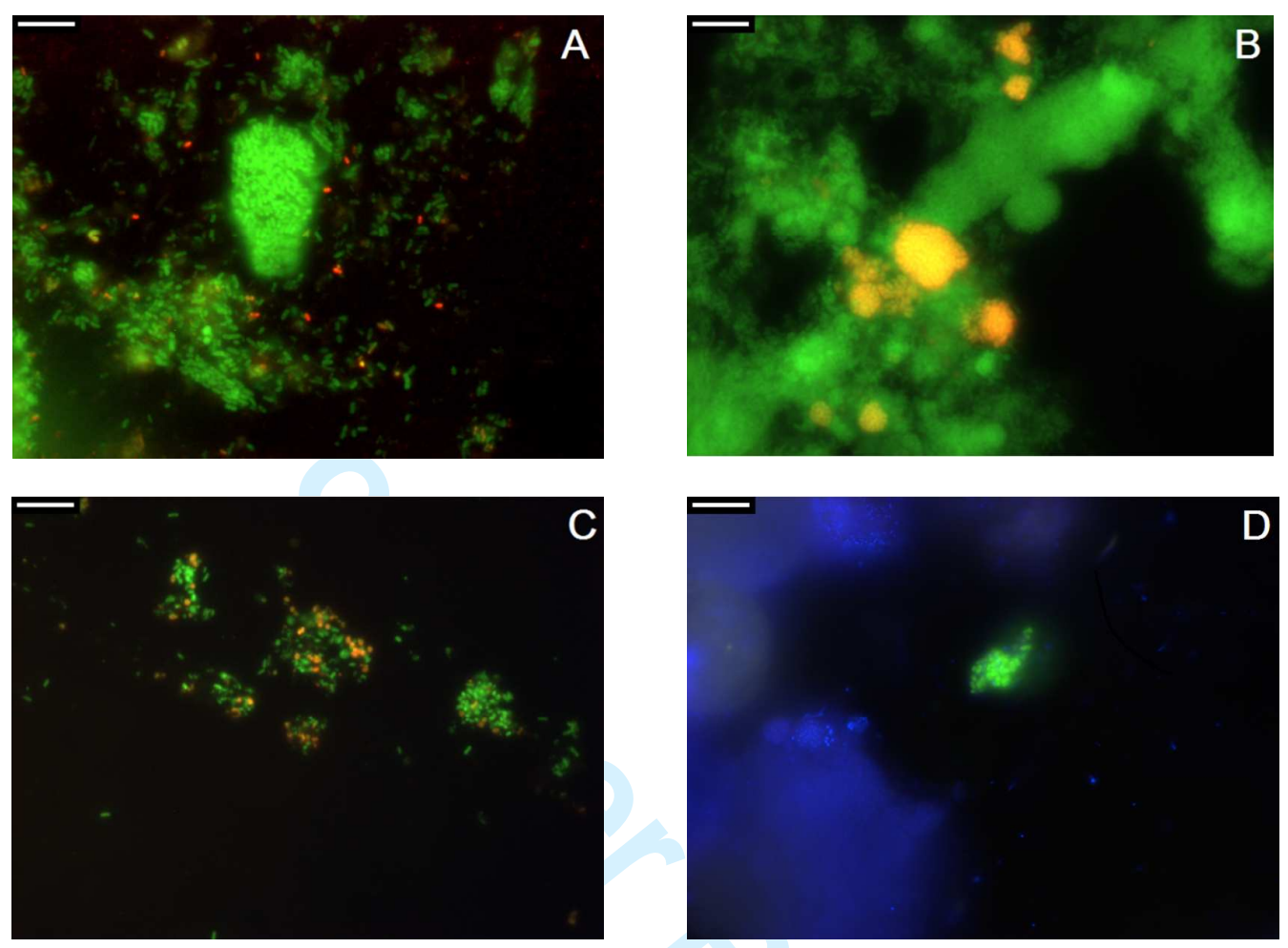

Figure 4 

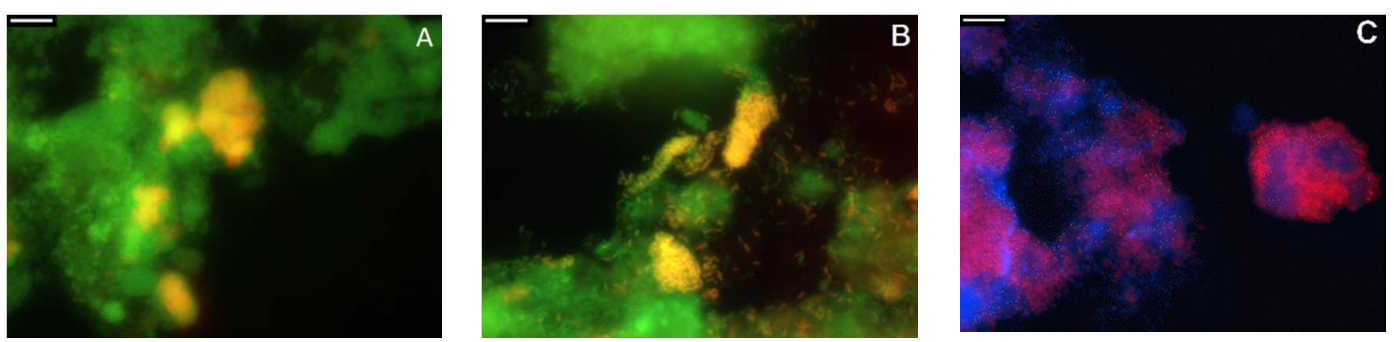

Figure 5

34

35

36

37

38

39

40

41

42

43

44

45

46

47

48

49

50

51

52

53

54

55

56

57

58

59

60

John Wiley \& Sons 


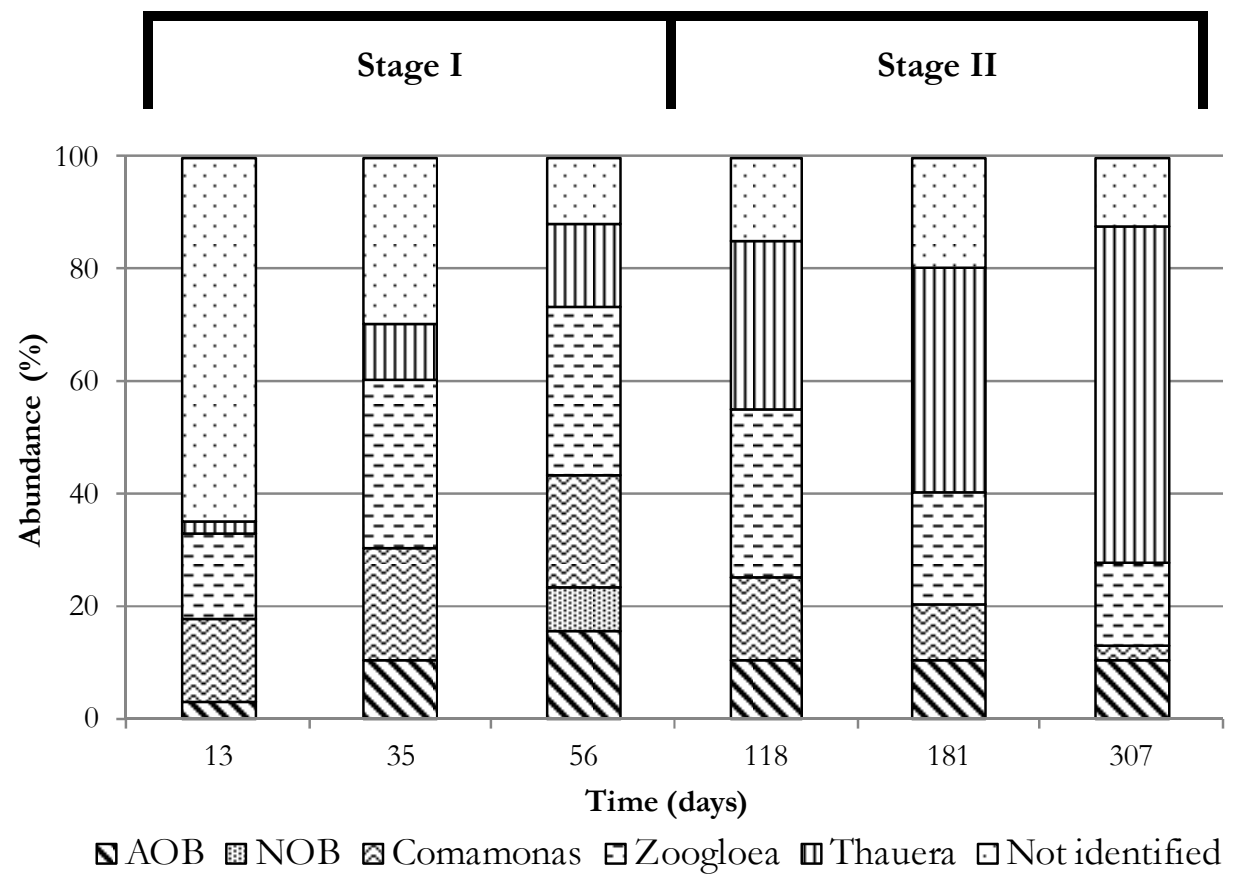

Figure 6 
Table 1. Sequence analysis of selected DGGE bands with the closest microorganisms and the corresponding percentages of similarity. The excised bands are labelled in Figure 1 (from 1 to 8 ).

\begin{tabular}{|c|c|c|c|c|}
\hline Band & $\begin{array}{c}\text { Accession } \\
\text { number }\end{array}$ & Closest organism & Phylogenetic group & $\begin{array}{c}\text { Similarity } \\
\mathbf{( \% )}\end{array}$ \\
\hline 1 & HM445153 & Uncultured bacterium clone GBL17O75 & Class Deltaproteobacteria & 99 \\
\hline 2 & KF037470 & Uncultured bacterium clone HF220 & Class Gammaproteobacteria & 97 \\
\hline 3 & HQ104073 & Uncultured Thauera sp. clone F5OHPNU07H90EJ & Genus Thauera & 100 \\
\hline 4 & JQ188096 & Uncultured bacterium clone BD11538 & Genus Brachymonas & 96 \\
\hline 5 & JX536887 & Uncultured Verrucomicrobiales bacterium clone 87 & Family Verrucomicrobiaceae & 97 \\
\hline 6 & KM296443 & Uncultured bacterium clone H7YL1YN01BBTIJ & Family Xanthomonadaceae & 92 \\
\hline 7 & JF703454 & Uncultured Xanthomonadaceae bacterium clone H2-58 & Family Xanthomonadaceae & 99 \\
\hline 8 & JF089056 & Uncultured bacterium clone ncd1279c07c1 & Family Comamonadaceae & 98 \\
\hline
\end{tabular}


2

3

4

5

6

7

8

9

10

11

12

13

14

15

16

17

18

19

20

21

22

23

24

25

26

27

28

29

30

31

32

33

34

35

36

37

38

39

40

41

42

43

44

45

46

47

48

49

50

51

52

53

54

55

56

57

58

59

60

Table 2. Resume of research works performed on the identification of microbial populations in aerobic granular systems.

\begin{tabular}{|c|c|c|c|c|c|c|c|}
\hline $\begin{array}{c}\text { Feeding } \\
\text { composition }\end{array}$ & $\mathrm{COD} / \mathrm{N}$ & $\begin{array}{c}\text { SBR } \\
(\mathrm{L})\end{array}$ & $\begin{array}{l}\text { Operation } \\
\text { (d) }\end{array}$ & $\begin{array}{c}\text { Removal } \\
\text { processes }\end{array}$ & $\begin{array}{c}\text { Studied } \\
\text { microorganisms }\end{array}$ & $\begin{array}{l}\text { Main identified } \\
\text { microorganisms }\end{array}$ & Ref \\
\hline $\begin{array}{l}\text { Anaerobically } \\
\text { pre-treated } \\
\text { abattoir ww }\end{array}$ & 6.7 & 5 & $>130$ & $\mathrm{COD}, \mathrm{N}, \mathrm{P}$ & $\begin{array}{c}\mathrm{PAO}^{a}, \mathrm{GAO}^{\mathrm{a}}, \mathrm{AOB}, \\
\mathrm{NOB}\end{array}$ & Accumulibacter spp. & {$[10]$} \\
\hline $\begin{array}{c}\text { Synthetic } \\
\text { media (acetate) }\end{array}$ & 12.9 & 4 & 157 & $\mathrm{COD}, \mathrm{N}, \mathrm{P}$ & $\begin{array}{c}\mathrm{PAO}, \mathrm{HB}, \mathrm{AOB}, \\
\text { NOB }\end{array}$ & $\begin{array}{c}\text { Accumulibacter, } \\
\text { Nitrosospira, Thauera }\end{array}$ & [12] \\
\hline $\begin{array}{c}\text { Synthetic } \\
\text { media (R1, R3: } \\
\text { acetate; R2: } \\
\text { propionate) }\end{array}$ & R1: 8.0 & 2.5 & R1: 220 & $\begin{array}{c}\text { R1: COD, } \\
\text { N, P } \\
\text { R2, R3: } \\
\text { COD, P }\end{array}$ & $\begin{array}{c}\mathrm{PAO}, \mathrm{GAO}, \mathrm{AOB}, \\
\mathrm{NOB}\end{array}$ & $\begin{array}{c}\text { Zoogloea, } \\
\text { Accumulibacter, } \\
\text { Competibacter }\end{array}$ & {$[13]$} \\
\hline Glucose & -- & 2.4 & 63 & COD & $\mathrm{HB}$ & $\begin{array}{c}\beta-, \gamma \text {-Proteobacteria, } \\
\text { Flavobacterium }\end{array}$ & [14] \\
\hline $\begin{array}{c}\text { Piggery } \\
\text { wastewater }+ \\
\text { glucose } \\
\end{array}$ & $17.6-28.6$ & 4 & 65 & $\mathrm{COD}, \mathrm{N}$ & $\begin{array}{l}\mathrm{HB}, \mathrm{AOB}, \mathrm{AOA}^{\mathrm{a}}, \\
\text { anammox }\end{array}$ & Thauera, Zoogloea & {$[15]$} \\
\hline $\begin{array}{c}\text { Synthetic } \\
\text { media (acetate) }\end{array}$ & 12.9 & 4 & 180 & $\mathrm{COD}, \mathrm{N}, \mathrm{P}$ & $\mathrm{AOB}, \mathrm{NOB}$ & Nitrosomonas & [29] \\
\hline Swine slurry & $\sim 6.2$ & 100 & 307 & $\mathrm{COD}, \mathrm{N}$ & $\mathrm{HB}, \mathrm{AOB}, \mathrm{NOB}$ & $\begin{array}{c}\text { Thauera, Zoogloea, } \\
\text { Comamonas, } \\
\text { Nitrosomonas }\end{array}$ & $\begin{array}{l}\text { This } \\
\text { work }\end{array}$ \\
\hline
\end{tabular}

a PAO: Phosphorous Accumulating Organisms; GAO: Glycogen Accumulating Bacteria; AOA: Ammonia Oxidizing Archaea 